\title{
Comment suivre les modifications de la position interne des triglycérides sériques humaines ?
}

Oléagineux, Corps Gras, Lipides. Volume 7, Numéro 1, 109-10, Janvier - Février 2000, Dossier : actes des Journées Chevreul "Corps gras, nutrition et santé, questions d'actualité" (Bordeaux, Pessac)

Auteur(s) : M. PINA, P. RENOUX, F. TURON, Y. CARO, B. BAREA, J. GRAILLE, Lipotechnie, CIRAD, Programme agroalimentaire, BP 5035, 34032, Montpellier Cedex 1.

\section{ARTICLE}

On sait que d'un point de vue nutritionnel chez l'homme sain, les acides gras de la position sn2 dans les triglycérides présentent la meilleure biodisponibilité après la digestion pancréatique.

Mais après absorption, comment suivre leurs incorporations et leurs évolutions (notamment les AGE) dans les triglycérides du sérum.

Compte tenu de la trop faible quantité de matériel biologique disponible, notamment dans le cadre d'une étude cinétique d'absorption, le problème à régler est analytique.

II n'y a pas actuellement de méthode adéquate pour déterminer la régiodistribution des triglycérides sériques circulants, d'où la nécessité de mettre au point un mode opératoire sur des quantités de triglycérides de l'ordre du milligramme.

Ce que nous avons fait en diluant la prise d'essai à analyser dans un ballast triglycéridique constitué d'acides gras non constitutifs des triglycérides à analyser.

Dans un premier temps, les conditions d'hydrolyse de la méthode normalisée (quantité de lipase, temps de réaction...) ont été adaptées à la diminution de la prise d'essai sur un corps gras témoin (huile de palme).

La composition en acides gras en sn2 des triglycérides déterminée selon la norme AFNOR NF.ISO.6800 sert de référence pour vérifier les résultats.

Les résultats sont satisfaisants sur $10 \mathrm{mg}$ de triglycérides et sur $1 \mathrm{mg}$ de triglycérides dilué dans $9 \mathrm{mg}$ de ballast (TCM C8 à C10).

Dans un second temps, les conditions optimales d'analyse du corps gras témoin ont été appliquées à l'étude des triglycérides du sang. L'analyse de la position centrale sur $1 \mathrm{mg}$ de triglycérides sériques est reproductible.

La lipase pancréatique n'étant pas strictement applicable à l'hydrolyse des triglycérides sériques, et les magnésiens étant inadaptés à la dégradation d'aussi faibles quantités de triglycérides car trop réactifs, nous proposons une microméthode qui autorise toutefois l'approche d'un suivi fiable des modifications de la position interne des triglycérides sanguins.

Le " point clé » quand on dispose de trop peu de matériel biologique est la notion de « dilution de la prise d'essai dans un ballast adapté » rendant ainsi opérationnelle la détermination. 